\title{
ERRATUM
}

\section{Health-related quality of life among disease-free stomach cancer survivors in Korea}

\author{
Jae-Moon Bae $\cdot$ Sung Kim · Young-Woo Kim $\cdot$ Keun Won Ryu \\ Jun Ho Lee · Jae-Hyung Noh · Tae-Sung Sohn · Seong-Kweon Hong • \\ Sang Min Park · Chang Hoon You · Jung Hee Kim · Myung Kyung Lee • \\ Young Ho Yun
}

Published online: 6 March 2007

(C) Springer Science+Business Media B.V. 2007

Erratum to: Qual Life Res (2006) 15: 1587-1596

DOI 10.1007/s11136-006-9000-8

The two article notes shown below were missing in the original publication.

Drs Jae-Moon Bae and Sung Kim contributed equally to this work as first authors.

Supported by National Cancer Center Grant 04101502.

The online version of the original article can be found at http://dx.doi.org/10.1007/s11136-006-9000-8

J.-M. Bae · Y.-W. Kim · K. W. Ryu · J. H. Lee .

S. M. Park · C. H. You · J. H. Kim · M. K. Lee ·

Y. H. Yun $(\bowtie)$

Research Institute and Hospital, Quality of Cancer Care

Branch, National Cancer Center, 809 Madu-dong, Ilsan-gu,

411-769 Goyang, Gyeonggi, Korea

e-mail: lawyun08@ncc.re.kr

S. Kim · J.-H. Noh · T.-S. Sohn · S.-K. Hong

Department of Surgery, Samsung Medical Center,

Sungkyunkwan University, Seoul, Korea 